\title{
lodine enhanced focused-ion-beam etching of silicon for photonic applications
}

\author{
Jonathan Schrauwen, ${ }^{\text {a) }}$ Dries Van Thourhout, and Roel Baets \\ Photonics Research Group, Department of Information Technology, Ghent University-IMEC, \\ 9000 Gent, Belgium
}

(Received 23 July 2007; accepted 21 September 2007; published online 26 November 2007)

\begin{abstract}
Focused-ion-beam etching of silicon enables fast and versatile fabrication of micro- and nanophotonic devices. However, large optical losses due to crystal damage and ion implantation make the devices impractical when the optical mode is confined near the etched region. These losses are shown to be reduced by the local implantation and etching of silicon waveguides with iodine gas enhancement, followed by baking at $300{ }^{\circ} \mathrm{C}$. The excess optical loss in the silicon waveguides drops from 3500 to $1700 \mathrm{~dB} / \mathrm{cm}$ when iodine gas is used, and is further reduced to $200 \mathrm{~dB} / \mathrm{cm}$ after baking at $300{ }^{\circ} \mathrm{C}$. We present elemental and chemical surface analyses supporting that this is caused by the desorption of iodine from the silicon surface. Finally we present a model to extract the absorption coefficient from the measurements. (C) 2007 American Institute of Physics.
\end{abstract}

[DOI: $10.1063 / 1.2815664]$

\section{INTRODUCTION}

The use of silicon as a platform for passive ${ }^{1-3}$ as well as active $^{4-7}$ photonics has been an exciting research subject in recent years. The research in this field is mainly driven by the telecommunications industry, looking for ways to make low-cost optical components for the consumer market. The primordial advantage of silicon over III-V materials is the large amount of experience that has been built up in electronics over the past decades, the availability of large and very reliable manufacturing environments, and the large refractive index contrast between silicon and oxide or air. Most of the micro- or nanophotonics structures in silicon are fabricated by a combination of optical lithography, dry and wet etching processes, layer deposition or growth, and molecular or polymer bonding. These are wafer-scale processes that enable fabrication of many devices in parallel, lowering the cost. However, due to the need for expensive masks, development of devices is costly and slow.

Therefore one needs prototyping technologies that enable rapid and flexible fabrication of nanophotonic components. The best example nowadays is electron-beam lithography, which is a serial technique, too slow for the mass fabrication of large devices, but attractive as prototyping technique because of its high resolution compared to standard optical lithography. One of the inconveniences however, is the fact that electrons cannot directly etch a semiconductor. Therefore one has to work with resist layers and etch with the classical tools such as plasma etching. This slows down the optimization process and limits the designs to planar structures. An interesting alternative is focused-ionbeam, where a beam of ions is used instead of an electron beam. In current commercial systems the particle optics enables local sputtering with a spot smaller than $10 \mathrm{~nm}$. There is no need for a resist, which enables the postprocessing of devices with a more complex topography such as ridge

${ }^{a)}$ Electronic mail: jonathan.schrauwen@intec.ugent.be waveguides. Further, one is no longer limited to etching planar structures, e.g., by tilting the sample one can etch slanted holes or slits. And when a machine with both electron and ion beam is used, one can directly inspect the fabricated device, which greatly accelerates the process optimization. As focused-ion beam is a serial technique it is not likely to be used for mass fabrication of large area devices. However, it would be a suitable technique to make small modifications to structures that were largely fabricated with other techniques such as optical lithography. Possible future applications are trimming of wavelength selective devices and etching of slanted facets.

Previous work has reported on the postprocessing of III-V devices, such as distributed feedback gratings in InP ridge waveguides, ${ }^{8}$ laser facets in $\mathrm{GaN},{ }^{9}$ distributed Bragg reflectors ${ }^{10}$ and photonic crystal cavity mirrors in InP. ${ }^{11}$ In all of these examples the modal volume is big compared to the etched region. A clear deterioration of the optical properties is often observed, but can be overcome by pumping in the undamaged regions. However, in silicon one is often limited to passive devices, and wants to exploit very tight confinement and small modal volumes. When a silicon device with its optical mode close to the focused-ion beam etched region is fabricated, large optical losses are observed, ${ }^{12-14}$ caused by amorphization and ion implantation of the silicon.

To enhance the focused-ion-beam etch rate one can use additional gasses in the etch process. ${ }^{15}$ It was also reported that the quality of active semiconductors is less deteriorated when gas enhancement is applied. ${ }^{16-18}$ In previous work we have reported that the quality of focused-ion-beam etched silicon is improved by iodine enhancement. ${ }^{12,19}$ In this work we present an in-depth investigation of this effect.

In Sec. II we will present our experimental setup: the transmission measurement of an implanted multimodal waveguide. In Sec. III we will elaborate on the measurement results and discuss the elemental and chemical analyses. 


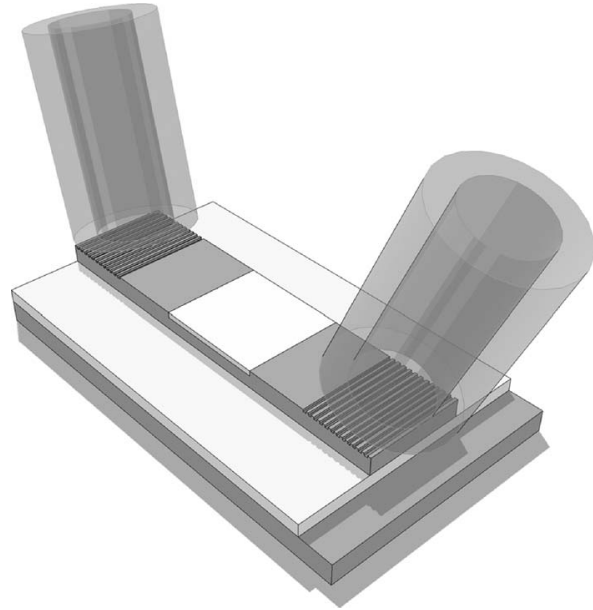

FIG. 1. Experiment: measurement of the transmitted optical power through implanted and etched silicon waveguides.

\section{EXPERIMENT}

\section{A. Implanting/etching waveguides}

To assess the losses induced in silicon by etching with a focused-ion beam, we have chosen to etch predefined broad waveguides on silicon on insulator wafers. The fabrication process of these multimodal waveguides was previously described, ${ }^{20,21}$ and consists of $248 \mathrm{~nm}$ optical lithography and inductively coupled plasma etching in a $\mathrm{HBr} / \mathrm{Cl}$ atmosphere. This process defines $10 \mu \mathrm{m}$ wide waveguides in a $220 \mathrm{~nm}$ thick crystalline silicon layer (slightly $p$-doped $\sim 10^{15} \mathrm{~cm}^{-3}$ ) on top of a $2 \mu \mathrm{m}$ thick oxide layer. These broad waveguides guide a fundamental mode at $1.55 \mu \mathrm{m}$ with an effective index nearly equal to that of the slab mode.

By scanning the ion beam across the top surface of these waveguides they are implanted and/or etched, depending on the dose of incident ions (Fig. 1). The experiments in this work are conducted with an FEI dual-beam 600, equipped with a $30 \mathrm{keV}$ gallium beam with minimal spot size of 10 $\mathrm{nm}$, and a $30 \mathrm{keV}$ electron beam for in situ inspection and ion-beam alignment. To enhance the etch process by iodine chemistry, our system is equipped with a gas nozzle that can be positioned near the etch site (at a distance of about $100 \mu \mathrm{m})$. The nozzle contains a crucible with solid $\mathrm{I}_{2}$ that is heated to about $42{ }^{\circ} \mathrm{C}$, causing the iodine to sublimate and adsorb to the silicon surface. In this way the background iodine pressure in the chamber is kept low, as it would disturb the particle optics.

The ion beam is scanned over the waveguide with a digital scanning algorithm: the beam moves to a certain location, the shutter opens during a certain dwell time and then closes, the beam is moved over a certain distance we will call pitch, and so on. The beam placement accuracy is limited by the 12 bit digital-to-analog converter (DAC) and can be calculated as one 4096th of the field of view. The smallest possible dwell time in our machine is $100 \mathrm{~ns}$. In the case of direct silicon etching the beam current was 300 pA. To have a homogeneous dose spread in the etched region it is sufficient to choose the pitch smaller than 1.5 times the beam width. $^{22}$ In our experiments we have chosen pitch $=(0.5$ $\times$ beam width). This would lead to DAC problems when a

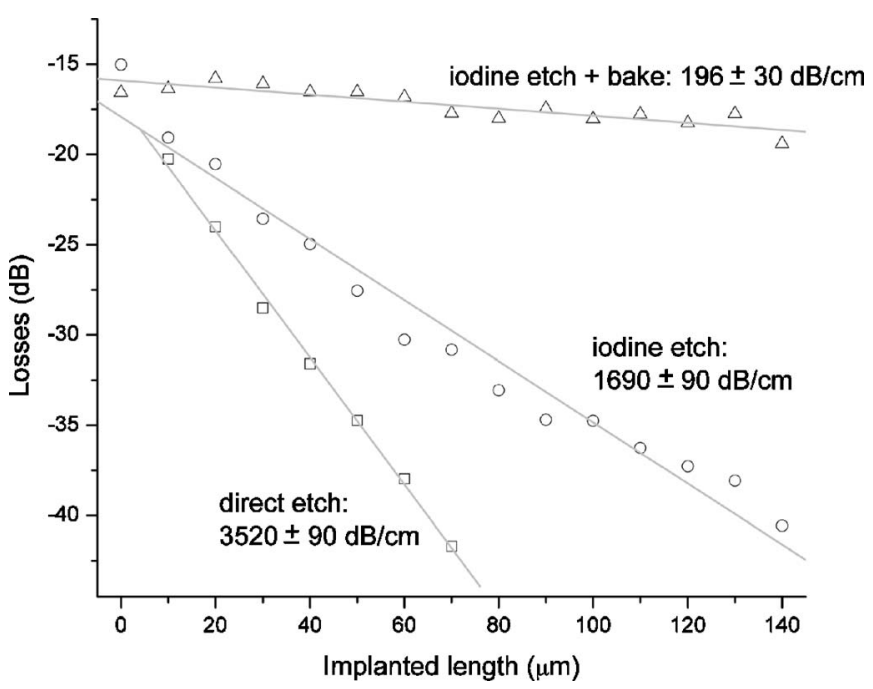

FIG. 2. Loss measurements for directly etched silicon waveguides ( $\square$ ), and iodine enhanced etched silicon waveguides before $(O)$ and after $(\triangle)$ thermal treatment.

large field is used with a small beam diameter. So we have chosen to give an extra blur by defocusing, to reach an actual beam diameter of $105 \mathrm{~nm}$, in contrast to the normal size of $33 \mathrm{~nm}$ for a $300 \mathrm{pA}$ beam. For a $10 \mu \mathrm{m} \times 10 \mu \mathrm{m}$ area and a $1 \mu$ s dwell time, a dose of $5 \times 10^{15} \mathrm{Ga} / \mathrm{cm}^{2}$ is delivered in 74 passes of $36.1 \mathrm{~ms}$ (2.67 $\mathrm{s}$ in total). In the case of enhanced etching a dwell time of $400 \mathrm{~ns}$ was chosen to avoid depletion of the adsorbed molecules. ${ }^{15}$ We have also chosen the pitch equal to the beam width, which leads to 831 passes of about $3.2 \mathrm{~ms}$ for equal dose and area. The samples for surface and ion profile analyses were prepared on a silicon wafer with $20 \mathrm{nA}$ on a $500 \mu \mathrm{m} \times 500 \mu \mathrm{m}$ area with a beam width of $1.6 \mu \mathrm{m}$.

\section{B. Loss measurements}

The broad silicon waveguides are provided with grating couplers to couple light from a single mode fiber to the chip and back (Fig. 1). $10 \mathrm{~mW}$ of light at a wavelength around $1.55 \mu \mathrm{m}$ is produced by a super luminescent light-emitting diode, is polarization controlled and coupled into the waveguide. The grating couplers will couple only the transverse electric fraction of the light into the waveguides. When the fibers are carefully aligned on top of the grating couplers the optical power is coupled only into the ground mode. The transmitted spectrum has a Gaussian shape ${ }^{23}$ and is measured by a spectrum analyzer with a bandwidth of $10 \mathrm{~nm}$. The transmitted power fraction is extracted from these spectra by taking the peak transmission. To measure the losses in the implanted or etched waveguides we use the cut back method: waveguides are implanted with the same dose over varying lengths. A linear fit of the optical losses in function of the implanted length yields the excess losses per unit length (Fig. 2). Each grating coupler has a loss of about $7 \mathrm{~dB}$ (slightly variable on different samples due to different exposure parameters or alignment issues), so the expected excess loss of an unimplanted waveguide is about $14 \mathrm{~dB}$. The sample length is 7 or $12 \mathrm{~mm}$, which makes the waveguide losses negligible (about $0.1 \mathrm{~dB} / \mathrm{cm}$ ). 


\section{RESULTS AND DISCUSSION}

\section{A. Direct etching of silicon: High optical losses}

Although gallium acts as a $p$-dopant in silicon, its use in electronics has been scarce due to the high diffusivity in $\mathrm{SiO}_{2}$, the low amorphization dose, ${ }^{24}$ and the relatively low solid solubility in silicon. ${ }^{25}$ In this work however, we are restricted to the use of gallium due to the limited commercial availability of other focused-ion beams.

It is known from TRIM calculations (transport and range of ions in matter $^{26}$ ) that a large number of gallium atoms are implanted into silicon per sputtered substrate atom, causing amorphization and implantation of silicon and thus high optical losses. To investigate these optical losses we have implanted broad waveguides as described in Sec. II A. We have chosen an implantation dose of $5 \times 10^{15} \mathrm{Ga}^{+} / \mathrm{cm}^{2}$ for two reasons. A primary reason is to aim for sufficiently high doses to have amorphization. From literature we have estimated that at $30 \mathrm{keV}$ a dose of $1 \times 10^{14} \mathrm{Ga}^{+} / \mathrm{cm}^{2}$ is sufficient to make an amorphous silicon layer. ${ }^{24,27-29}$ A secondary reason is not to etch away too large a fraction from the silicon waveguide not to encounter mode mismatch losses. It was reported in Refs. 30 and 31 that silicon swells at low dose implantations (typically $<5 \times 10^{15}$ ) and starts etching at higher doses. So we expect no net etching in our experiment, which was confirmed by measuring the depth profile afterwards.

By TRIM calculations we have estimated an amorphization depth of approximately $50-60 \mathrm{~nm}$, which is confirmed by Ref. 32. The peak concentration (at a depth of $28 \mathrm{~nm}$ ) in our experiment is expected to be about $1.8 \times 10^{21} \mathrm{Ga}^{+} / \mathrm{cm}^{3}$, or 3.6 at. \% (The experimental verification will be discussed later). This is far above the solid solubility of gallium in silicon at room temperature $\left[10^{19} \mathrm{Ga}^{+} / \mathrm{cm}^{3}\right.$ (Ref. 25)]. However, due to the low diffusivity of gallium in silicon, this configuration is stable at room temperature. Due to the low amorphization dose we do not expect any channeling effects, so all implantations were performed perpendicular to the surface.

The results are plotted in Fig. 2 (data points marked with $\square)$. We have measured a loss of $3520 \pm 90 \mathrm{~dB} / \mathrm{cm}$ for directly etched waveguides. To compare this to the expected material losses $(\alpha$ in $\mathrm{dB} / \mathrm{cm})$ due to free carriers we will assume a homogeneous dose of $1 \times 10^{21} \mathrm{Ga}^{+} / \mathrm{cm}^{3}$ in the top $50 \mathrm{~nm}$ layer of the waveguide. According to Ref. 33 this would lead to $\alpha=6000 \mathrm{~cm}^{-1}$, assuming that all gallium atoms are electrically active. Due to limited overlap between the fundamental mode and the lossy region the modal losses will be lower. We have computed the losses of the fundamental mode in this case: about $2500 \mathrm{~dB} / \mathrm{cm}$. This proves that, even if all gallium atoms would be electrically active, the losses we have measured cannot only be explained by carrier absorption.

It is clear that these losses are too high to make useful devices where the optical mode is confined near the etched region, e.g., photonic crystals. It was pointed out in Ref. 14 that the gallium atoms can be removed by high temperature annealing $\left(800^{\circ} \mathrm{C}\right)$. But as we are interested in focused-ion beam as a postprocessing technique, where metal is contact-

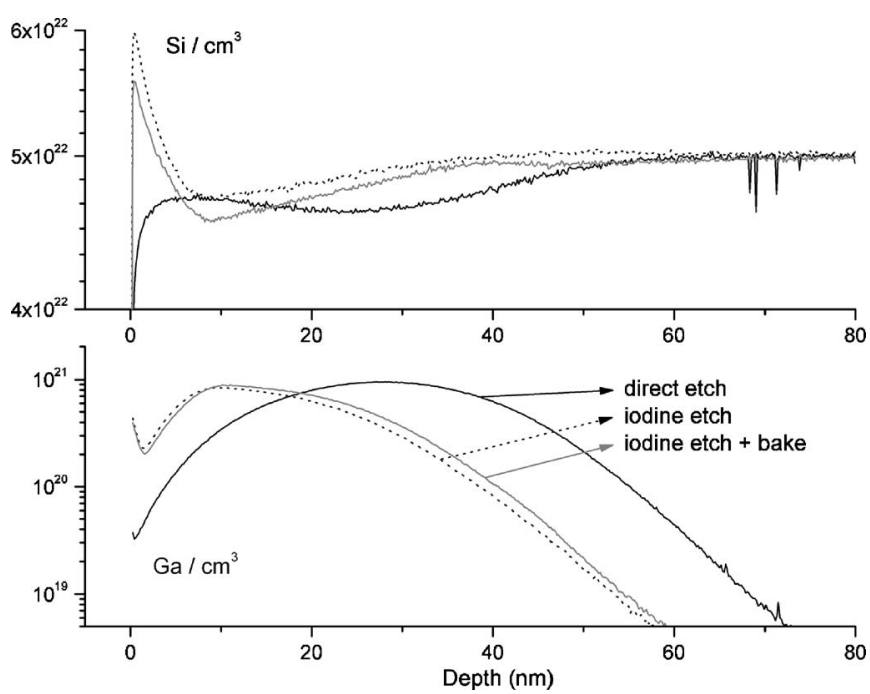

FIG. 3. Depth concentration profiles for $\mathrm{Si}$ and $\mathrm{Ga}$, obtained by secondary ion mass spectroscopy (SIMS). The implantation depth in the case of iodine enhancement is significantly lower, and baking at $300{ }^{\circ} \mathrm{C}$ only slightly alters the profile.

ing silicon or III-V materials are bonded on silicon, high temperatures are not desirable. For this reason we have looked for a low temperature alternative to reduce optical losses: chemically enhanced etching.

\section{B. lodine enhanced etching}

On impact at the etch site, the iodine atoms adsorb to the silicon surface, ${ }^{34-37}$ creating $\mathrm{SiI}_{x}$ bonds. The species formed in this reaction are involatile at room temperature, so the silicon surface will not be etched without extra heating. However, when gallium atoms impact on the surface and disturb the thermodynamic equilibrium, the silicon-iodine molecules can desorb and are pumped away in the vacuum system, so the surface is etched. This process greatly enhances the etch rate, as was also reported for other adsorbed halogens. ${ }^{38}$

Figure 2 (data points marked as $\bigcirc$ ) shows the measured excess losses in waveguides etched with the same dose as previously $\left(5 \times 10^{15} \mathrm{Ga}^{+} / \mathrm{cm}^{2}\right)$, but with iodine atoms adsorbed to the surface. From the measurements we have extracted an excess loss of $1690 \pm 90 \mathrm{~dB} / \mathrm{cm}$. This is proof of less optical absorption in halogen enhanced focused-ion beam etched silicon. Similar results were reported for the photoluminescence of GaAs in the case of chlorine etch enhancement. ${ }^{16-18}$

Secondary ion mass spectroscopy (SIMS) was performed (with a $500 \mathrm{eV}$ oxygen beam and final crater depth of 200-300 nm) to investigate the depth profile of $\mathrm{Ga}$ in the case of direct etching and iodine enhanced etching. The results are depicted in Fig. 3. The Ga profile is the sum of both stable isotopes that were measured separately. A primary observation is the peak dose for the direct etch: from TRIM calculations we had expected a dose of $1.8 \times 10^{21} \mathrm{Ga}^{+} / \mathrm{cm}^{3}$, whereas the graph shows only $1.0 \times 10^{21} \mathrm{Ga}^{+} / \mathrm{cm}^{3}$. By integrating over the entire depth range we have calculated a real area dose of $2.99 \times 10^{15} \mathrm{Ga}^{+} / \mathrm{cm}^{2}$, instead of the exposed $5 \times 10^{15} \mathrm{Ga}^{+} / \mathrm{cm}^{2}$. In the case of iodine enhancement this 


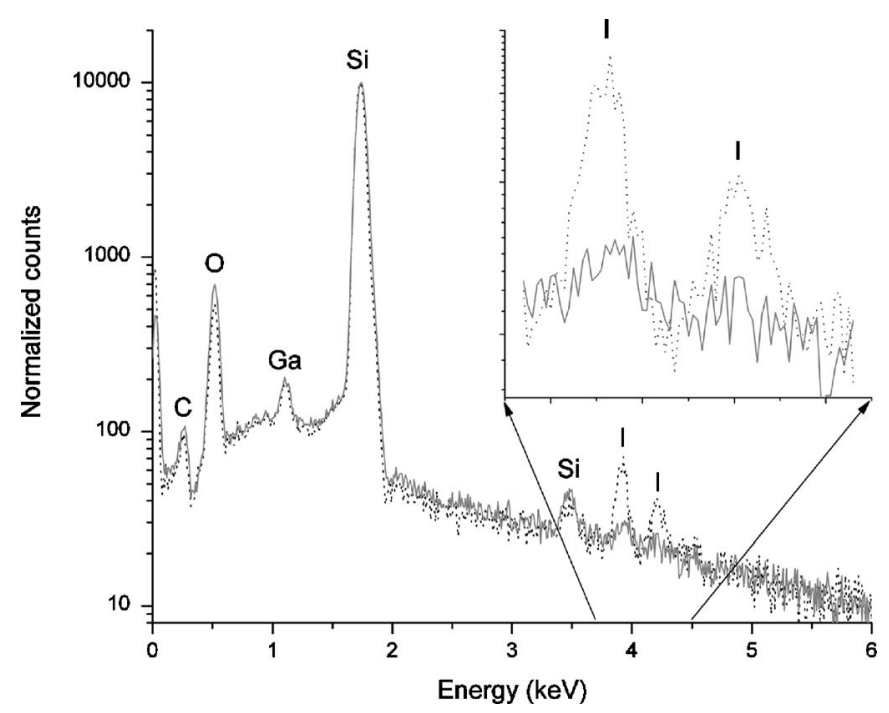

FIG. 4. Graph of the energy dispersive x-ray (EDX) analysis before (black dotted) and after (gray) thermal treatment at $300{ }^{\circ} \mathrm{C}$. The inset zooms in on the iodine peaks, and shows that the iodine content of the sample surface noticeably decreases during the treatment.

discrepancy is even bigger with a real area dose of 1.98 $\times 10^{15} \mathrm{Ga}^{+} / \mathrm{cm}^{2}$. Although we do not have an explanation for this discrepancy, the doses are still sufficiently high to amorphize silicon and our further conclusion will not be altered.

It is also clear from the graph that the silicon density is lower in the regions where the gallium dose is high, which we expect due to amorphization and swelling. The Si profile for the enhanced etches suggests a higher Si density near the surface, however, this might only seemingly be so due to the higher ionization rate in the SIMS measurement due to the presence of iodine near the surface. Another observation is the shallower implantation depth in the case of iodine enhanced etch: the peak dose has shifted from 28 to $11 \mathrm{~nm}$ when iodine enhancement is applied. A bake step at $300{ }^{\circ} \mathrm{C}$ (see further) does not noticeably alter the depth profile.

\section{C. lodine desorption by thermal treatment}

Most of the iodine-silicon bonds created by the ion bombardment are not volatile at room temperature, and possibly remain on the surface. Therefore, we have baked the samples for $2 \mathrm{~h}$ on a hot plate at $300{ }^{\circ} \mathrm{C}$ in $\mathrm{N}_{2}$. The optical measurements of samples implanted with equal dose (5 $\times 10^{15} \mathrm{Ga}^{+} / \mathrm{cm}^{2}$ ) with iodine and thermal treatment show a remarkable decrease in excess optical losses, as shown in Fig. 2 (data points marked with $\triangle$ ). We have measured a loss of $196 \pm 30 \mathrm{~dB} / \mathrm{cm}$.

To verify the chemical and elemental composition of the etched and/or baked surface we have performed energy dispersive X-ray spectroscopy (EDX, see Fig. 4) and X-ray photoemission spectroscopy (XPS, see Fig. 5) analyses.

The EDX analysis was done at grazing incidence with $10 \mathrm{keV}$ electrons to give as much information as possible about the composition of the surface. However, a Monte Carlo simulation has taught us that the interaction volume in this analysis is still at least $500 \mathrm{~nm}$. So this analysis will mainly probe the silicon bulk. From the graph in Fig. 4 we
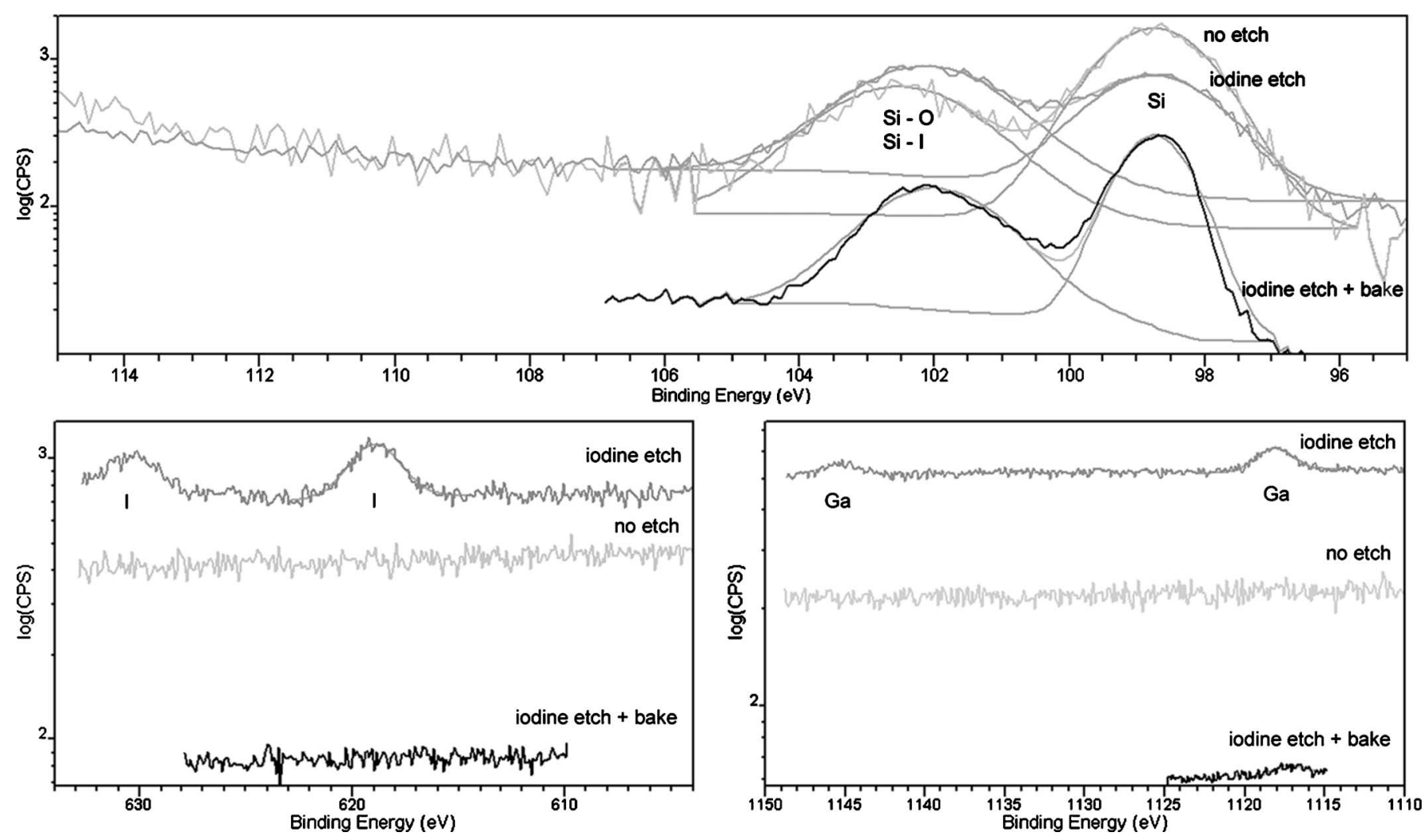

FIG. 5. X-ray photoemission spectroscopy (XPS) of silicon before etching (without native oxide removal), etched with iodine enhancement and etched with iodine and baked at $300^{\circ} \mathrm{C}$. After baking there is an obvious decrease of iodine and gallium content at the surface. 
can clearly see that the amount of iodine decreases after baking, whereas the gallium content remains constant. This is as expected since the diffusion of gallium in silicon is slow, even at $300{ }^{\circ} \mathrm{C}$, and is also supported by the SIMS measurement in Fig. 3.

To gain more insight in the surface composition of the samples we have conducted an XPS analysis. X-ray generated photo-electrons give information about the occupied energy levels of the surface atoms, from which we can deduce the element and its chemical state. The photoemission spectra are presented in Fig. 5. To eliminate any charging effects that would change the Fermi level in the bulk silicon, we have calibrated all measurements by shifting the $\mathrm{Si}$ bulk component to $98.74 \mathrm{eV}^{37}$ We have measured three samples: a nonetched Si sample without native oxide removal; an iodine etched sample; and an iodine etched and baked sample. The latter was measured with somewhat higher energy resolution, giving rise to a lower count rate and narrower peaks. The nonetched sample shows no presence of gallium nor iodine, as expected. Further the peak around $102 \mathrm{eV}$ shows the presence of native oxide. It was reported in Ref. 35 that upon iodine adsorption extra silicon peaks appear about $1 \mathrm{eV}$ higher than the bulk component. These are due to the adsorption of iodine and saturation of dangling bonds, followed by the formation of the $\mathrm{Si}^{+}$and $\mathrm{Si}^{2+}$ oxidation states at higher iodine saturation. These experiments were conducted with synchrotron-based photoelectron spectroscopy and visualize very small energy shifts that are impossible to resolve in our commercial XPS system. However, we can still draw some useful conclusions from the photoemission spectra. After iodine enhanced etching the $\mathrm{SiO}_{2}$ peak becomes more significant and slightly shifts to the right, whereas an iodine peak appears near $620 \mathrm{eV}$, suggesting the presence of siliconiodine bonds. There is also a noticeable amount of gallium in the sample. After baking for $2 \mathrm{~h}$ at $300{ }^{\circ} \mathrm{C}$, the $\mathrm{SiO}_{2}$ peak weakens again, but a small shift to lower binding energy remains. Further, the iodine peak disappears and the gallium peak weakens. This suggest that much of the $\mathrm{SiI}_{x}$ bonds have disappeared during baking, whereas the chemical nature of the silicon surface layer is slightly altered. The reduction of the gallium component suggests that part of the implanted ions are captured in a surface layer during etching, and desorb with the $\mathrm{SiI}_{x}$ bonds.

\section{Amorphization}

To verify the crystallinity after etching we have performed electron backscatter diffraction with $5 \mathrm{keV}$ electrons at $70^{\circ}$ incidence. As displayed in Fig. 6, the diffraction of electrons on lattice plains shows a clear pattern for nonetched crystalline silicon. The same analysis was carried out on directly etched and iodine etched samples (as described in Sec. II), yielding amorphization in both cases. Baking for $2 \mathrm{~h}$ at $300{ }^{\circ} \mathrm{C}$ nor a $6 \mathrm{~min}$ anneal at $700{ }^{\circ} \mathrm{C}$ succeed in recrystallizing the etched surface. This is in contradiction with what was previously reported for recrystallization of gallium implanted silicon. ${ }^{24,27,39,40}$ However, previous work has not

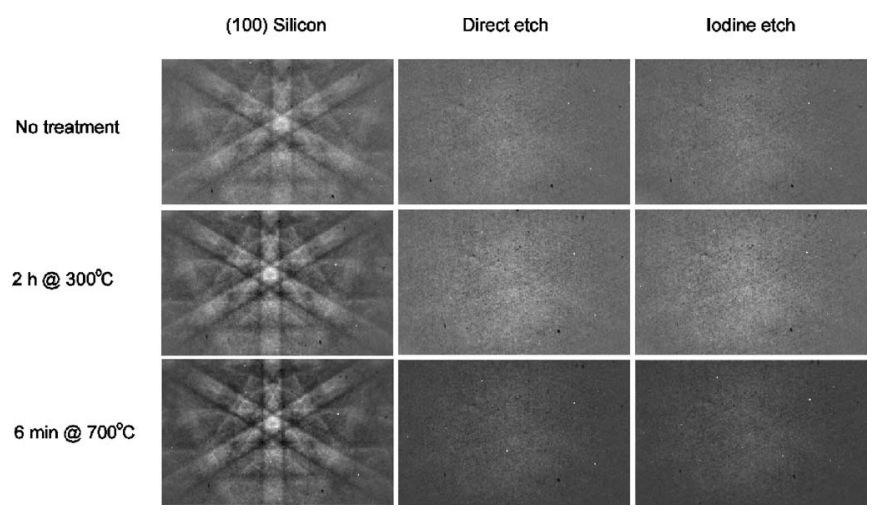

FIG. 6. Electron backscatter diffraction (EBSD) micrographs showing the amorphization after etching. The surface is not recrystallized after a 6 min anneal at $700{ }^{\circ} \mathrm{C}$, in contradiction with what we expect from literature.

reached implantations as high as some atomic percent. The very high degree of contaminants in the silicon likely disturbs the recrystallization process.

\section{E. Higher doses}

Up to now we have used a dose of $5 \times 10^{15} \mathrm{Ga}^{+} / \mathrm{cm}^{2}$. Waveguides that are exposed to this dose do not undergo substantial etching. So to investigate the optical losses of more realistic structures etched with iodine enhancement, we have etched the waveguides with higher doses but on sections with an equal length $(25 \mu \mathrm{m})$. The maximum dose, 1 $\times 10^{17} \mathrm{Ga}^{+} / \mathrm{cm}^{2}$, etches away the complete $220 \mathrm{~nm}$ silicon layer. As minimal dose we have chosen $2 \times 10^{15} \mathrm{Ga}^{+} / \mathrm{cm}^{2}$. For each dose we have measured the excess optical losses as well as the depth of the etched region before and after a $2 \mathrm{~h}$ bake at $300{ }^{\circ} \mathrm{C}$. The etch depth was measured with an optical profilometer (Veeco Wyko NT3000) after depositing 100 $\mathrm{nm}$ of gold. The results are displayed in Fig. 7, where the experimental uncertainty for the measurements is illustrated by the size of the data points.

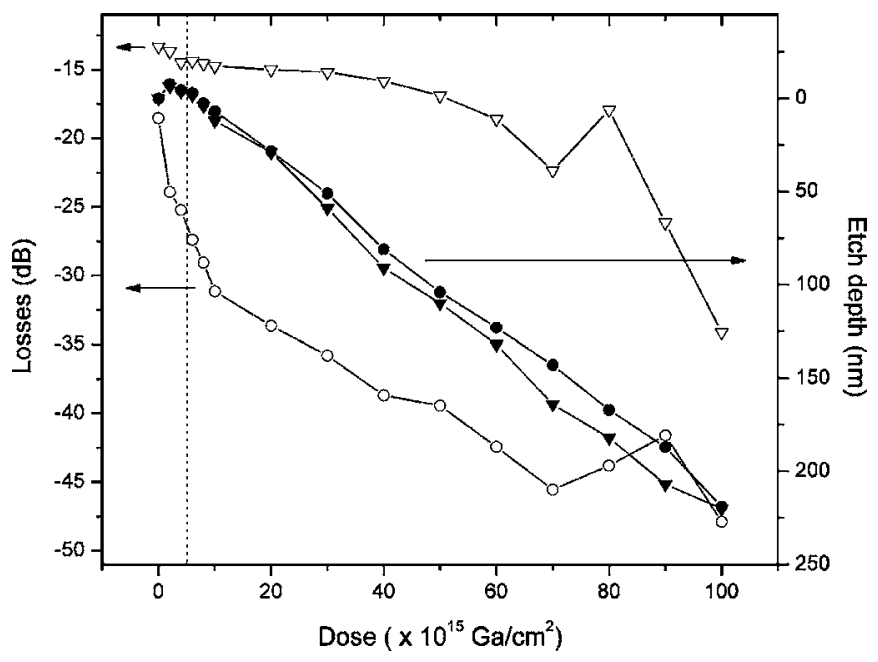

FIG. 7. Optical losses, including $14 \mathrm{~dB}$ of the fiber couplers, of the iodine etched sample before $(\bigcirc)$ and after $(\nabla)$ baking at $300{ }^{\circ} \mathrm{C}$, and the etch depth measured by an optical profilometer before $(\boldsymbol{O})$ and after $(\boldsymbol{\nabla})$ baking. The dotted vertical line indicates the dose used in previous experiments. The optical losses after baking remain rather constant up to an etch depth of about $100 \mathrm{~nm}$. 


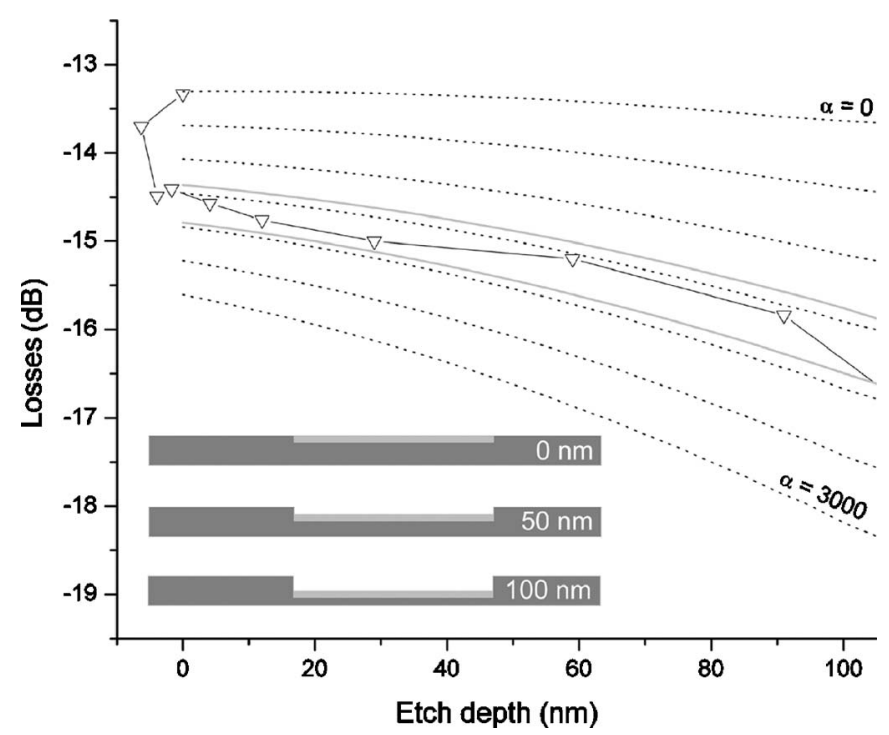

FIG. 8. Losses as a function of the measured etch depth $(\nabla)$. The negative depth accounts for swelling of the material. The dotted lines represent the simulated losses for a layer with $40 \mathrm{~nm}$ thickness and different loss coefficients, whereas the gray lines represent the losses for a layer with varying thickness and a loss coefficient of $1650 \mathrm{~cm}^{-1}$. A schematic representation of the model is shown in the inset.

The depth measurement shows that the samples swell at low dose implantation under iodine atmosphere, similar to swelling by direct gallium implantation. ${ }^{30,31}$ However, we expect possible extra swelling due to the formation of adsorbed $\mathrm{SiI}_{x}$ species on the sample surface. The overall etch depth after baking is significantly deeper, which also supports the fact that $\mathrm{SiI}_{x}$ is desorbed from the silicon surface. The reduction of the optical losses in the etched structure by desorbing iodine bonds is obvious.

\section{F. Calculation of material losses after iodine desorption}

In Fig. 8 the data points from Fig. 7 are replotted, but as a function of the measured etch depth instead of the exposed dose. The negative depths are due to swelling at low doses. We want to extract the average material losses in the implanted section and for that purpose use the following model. From the SIMS data we have estimated the depth of the amorphous silicon layer to be $40 \mathrm{~nm}$. We have assumed that this layer has a refractive index of 3.7 , with a variable imaginary part to fit the material losses to the experimental data points. The power transmitted through a $25 \mu \mathrm{m}$ etched waveguide region, as displayed in the inset of Fig. 8, is calculated in a two-dimensional simulation with a mode expansion tool. This was done at a fixed wavelength of $1.55 \mu \mathrm{m}$, taking into account 50 modes in the vertical direction. For deeply etched waveguides this model becomes invalid due to large reflections and radiative losses, so we take etch depths up to $100 \mathrm{~nm}$ into account, as displayed in the inset of Fig. 7. We have also displayed the simulated losses for material loss varying from 0 to $3000 \mathrm{~cm}^{-1}$ in steps of $500 \mathrm{~cm}^{-1}$. An offset of $-13.3 \mathrm{~dB}$ (the zero dose data point from Fig. 7) was applied to account for the losses in the fiber couplers. From these simulations we have estimated a loss coefficient of $1650 \pm 250 \mathrm{~cm}^{-1}$ in the amorphized silicon layer. The gray lines represent the simulated losses for a layer with a loss of $1650 \mathrm{~cm}^{-1}$ and a thickness of 35 and $45 \mathrm{~nm}$.

\section{CONCLUSIONS}

We have performed optical loss measurements on predefined silicon on insulator waveguides that were implanted and etched by focused-ion beam. Direct etching yields very high losses, compromising the usefulness of this technique for the fabrication of photonic components where the optical mode is confined near the etched region. However, by using iodine as etch enhancement gas and by performing a thermal treatment at $300{ }^{\circ} \mathrm{C}$ we have drastically reduced the optical losses in silicon. Examination of the etched surface suggests that the treatment is necessary to desorb silicon-iodine bonds from the surface. We have estimated the resulting material losses in the etched region by fitting a simplified model to our data. We believe that iodine enhanced etching is a promising technique for the postprocessing of photonic devices in silicon.

\section{ACKNOWLEDGMENTS}

This work was partly supported by the European Union through the Network of Excellence ePIXnet, by the Belgian IAP-PHOTON network and the Fund for Scientific Research (FWO).

${ }^{1}$ T. Tsuchizawa, K. Yamada, H. Fukuda, T. Watanabe, J. Takahashi, M. Takahashi, T. Shoji, E. Tamechika, S. Itabashi, and H. Morita, IEEE J. Sel. Top. Quantum Electron. 11, 232 (2005).

${ }^{2}$ P. Dumon, W. Bogaerts, D. Van Thourhout, D. Taillaert, R. Baets, J. Wouters, S. Beckx, and P. Jaenen, Opt. Express 14, 664 (2006).

${ }^{3}$ Q. F. Xu, B. Schmidt, S. Pradhan, and M. Lipson, Nature (London) 435, 325 (2005).

${ }^{4}$ H. S. Rong, R. Jones, A. S. Liu, O. Cohen, D. Hak, A. Fang, and M. Paniccia, Nature (London) 433, 725 (2005).

${ }^{5}$ G. Roelkens, D. Van Thourhout, R. Baets, R. Notzel, and M. Smit, Opt. Express 14, 8154 (2006).

${ }^{6}$ A. W. Fang, R. Jones, H. Park, O. Cohen, O. Raday, M. J. Paniccia, and J. E. Bowers, Opt. Express 15, 2315 (2007).

${ }^{7}$ J. Van Campenhout, P. Rojo Romeo, P. Regreny, C. Saessal, D. Van Thourhout, S. Verstuyft, L. Di Cioccio, J.-M. Fedeli, C. Lagahe, and R. Baets, Opt. Express 15, 6744 (2007).

${ }^{8}$ S. Rennon, L. Bach, H. Konig, J. P. Reithmaier, A. Forchel, J. L. Gentner, and L. Goldstein, Microelectron. Eng. 57-58, 891 (2001).

${ }^{9}$ A. J. Steckl and I. Chyr, J. Vac. Sci. Technol. B 17, 362 (1999).

${ }^{10}$ Q. Ren, B. Zhang, J. Xu, Z. S. Zhang, Y. B. Jin, Y. Qian, and D. P. Yu, Solid State Commun. 130, 433 (2004).

${ }^{11}$ T. Stomeo, G. Visimberga, M. T. Todaro, A. Passaseo, R. Cingolani, M. De Vittorio, S. Cabrini, A. Carpentiero, and E. Di Fabrizio, Microelectron. Eng. 78-79, 417 (2005).

${ }^{12}$ J. Schrauwen, D. Van Thourhout, and R. Baets, Appl. Phys. Lett. 89, 141102 (2006).

${ }^{13}$ D. J. Moss, V. G. Ta'eed, B. J. Eggleton, D. Freeman, S. Madden, M. Samoc, B. Luther-Davies, S. Janz, and D. X. Xu, Appl. Phys. Lett. 85, 4860 (2004).

${ }^{14}$ Y. Tanaka, M. Tymczenko, T. Asano, and S. Noda, Jpn. J. Appl. Phys., Part 1 45, 6096 (2006).

${ }^{15}$ K. Edinger and T. Kraus, Microelectron. Eng. 57-58, 263 (2001).

${ }^{16}$ M. Taneya, Y. Sugimoto, and K. Akita, J. Appl. Phys. 66, 1375 (1989).

${ }^{17}$ Y. Sugimoto, M. Taneya, H. Hidaka, and K. Akita, J. Appl. Phys. 68, 2392 (1990).

${ }^{18}$ Y. Sugimoto, M. Taneya, K. Akita, and H. Hidaka, J. Appl. Phys. 68, 6415 (1990).

${ }^{19}$ J. Schrauwen, F. Van Laere, D. Van Thourhout, and R. Baets, IEEE Photonics Technol. Lett. 19, 816 (2007).

${ }^{20}$ W. Bogaerts, D. Taillaert, B. Luyssaert, P. Dumon, J. Van Campenhout, P. Bienstman, D. Van Thourhout, R. Baets, V. Wiaux, and S. Beckx, Opt. 
Express 12, 1583 (2004)

${ }^{21}$ W. Bogaerts, R. Baets, P. Dumon, V. Wiaux, S. Beckx, D. Taillaert, B Luyssaert, J. Van Campenhout, P. Bienstman, and D. Van Thourhout, J. Lightwave Technol. 23, 401 (2005).

${ }^{22}$ A. A. Tseng, J. Micromech. Microeng. 14, R15 (2004).

${ }^{23}$ D. Taillaert, P. Bienstman, and R. Baets, Opt. Lett. 29, 2749 (2004).

${ }^{24}$ M. Y. Tsai, B. G. Streetman, V. R. Deline, and C. A. Evans, J. Electron. Mater. 8, 111 (1979).

${ }^{25}$ A. H. Vanommen, J. Appl. Phys. 56, 2708 (1984).

${ }^{26}$ J. F. Ziegler, Nucl. Instrum. Methods Phys. Res. B 219-220, 1027 (2004)

${ }^{27}$ C. H. Chu, Y. F. Hsieh, L. R. Harriott, and H. H. Wade, J. Vac. Sci. Technol. B 9, 3451 (1991).

${ }^{28}$ R. R. Hart, C. L. Anderson, H. L. Dunlap, R. L. Seliger, and V. Wang, Appl. Phys. Lett. 35, 865 (1979).

${ }^{29}$ M. Tamura, S. Shukuri, M. Moniwa, and M. Default, Appl. Phys. A: Solids Surf. A39, 183 (1986).
${ }^{30}$ A. Lugstein, B. Basnar, G. Hobler, and E. Bertagnolli, J. Appl. Phys. 92, 4037 (2002).

${ }^{31}$ B. D. Huey and R. M. Langford, Nanotechnology 14, 409 (2003).

${ }^{32}$ S. Rubanov and P. R. Munroe, J. Microsc. 214, 213 (2004).

${ }^{33}$ R. A. Soref and J. P. Lorenzo, IEEE J. Quantum Electron. 22, 873 (1986).

${ }^{34}$ V. Chakarian, D. K. Shuh, J. A. Yarmoff, M. C. Hakansson, and U. O. Karlsson, Surf. Sci. 296, 383 (1993).

${ }^{35}$ D. Rioux, F. Stepniak, R. J. Pechman, and J. H. Weaver, Phys. Rev. B 51, 10981 (1995).

${ }^{36}$ C. M. Aldao and J. H. Weaver, Prog. Surf. Sci. 68, 189 (2001).

${ }^{37}$ Y. Yang and J. A. Yarmoff, Surf. Sci. 573, 335 (2004).

${ }^{38}$ R. J. Young, J. R. A. Cleaver, and H. Ahmed, J. Vac. Sci. Technol. B 11, 234 (1993).

${ }^{39}$ H. C. Mogul and A. J. Steckl, IEEE Electron Device Lett. 14, 123 (1993).

${ }^{40}$ A. Pan, Y. L. Wang, C. S. Wu, C. D. Chen, and N. W. Liu, J. Vac. Sci. Technol. B 23, 2288 (2005). 